\title{
Fishing vessel queue model in Kutaraja Fishing Port: Case study of Wharf Pias II
}

\author{
Rosi Rahayu ${ }^{1}$, Muhammad Muhammad ${ }^{*}$, Kurnia Kurnia ${ }^{3}$, and Zakyatul Muna ${ }^{4}$ \\ ${ }^{1}$ Department of Fisheries Resource Utillization, Faculty of Marine and fisheries, Universitas Syiah Kuala, 23111, Banda Aceh, \\ Indonesia \\ ${ }^{2}$ Department of Marine Science, Faculty of Marine and Fisheries, Universitas Syiah Kuala, 23111, Banda Aceh, Indonesia \\ ${ }^{3}$ Department of Fisheries Resource Utillization, Faculty of Marine and fisheries, Abulyatama University, 23372, Banda Aceh, \\ Indonesia \\ ${ }^{4}$ Post Graduate Student of Marine and Fisheries Technology, Faculty of Fisheries and Marine. Bogor Agriculture University, 16680 , \\ Bogor, Indonesia.
}

\begin{abstract}
Kutaraja international Fishing Port is one of the biggest port with highest activity in Aceh Province. Nevertheless, when unloading process, fishing vessel often occur long queue of fishing vessel. This study aims to identify the vessel queue landed in Kutaraja Fishing Port, identify the degree of usefulness of the system utility of unloading fasilities and identify the vessel waiting time in the queue at Kutaraja Fisng port. The methods used was case study and standard formula of multi channel single phase. The results showed that the model queue that occurred in Kutaraja Fishing Port was (M/M/4): (FCFS / I / I). Based on calculations by the standard formula queuing model, it was obtained that the rate of arrival of the vessel unloading was 22 vessels/day and the rate of the service time was 16 vessels/day. Value of waiting time in the queue was 0 hour and the number of vessels that queue do not exist, while the waiting time in the system was 3,4 hours and the number of vessel arriving in the system was 1,42 units. The result of the calculation also showed that utility value of the system almost reached the optimum value $(1,37)$ and the probably no vessel in a system was 0,08 . The efforts that can be made to accelerate the performance of fish demolition in Kutaraja Fishing Port, namely using cranes as tools when unloading fish on fishing vessel.
\end{abstract}

\section{Introduction}

The increasing status of Kutaraja International Fishing Port from type $\mathrm{C}$ to type A brings many changes to the fishing port activities. in addition, after the fishing port relocated to a new place, Kutaraja International Fishing Port also has changes in terms, one of them is facilities [1] [2]. One of the facilities that has undergone changes is main facilities. The main facility is one of the most prioritized facilities in the Port because it serves as a protector for fishing vessels that land their catch from waves or other damage [3].

One type of basic facility that has undergone changes in Kutaraja International Fishing Port is the wharf. At the previous location, the length of the wharf was only $80 \mathrm{~m}$ and in the currently location became 100 $\mathrm{m}$ [4]. There is an increase in infrastructure that occurs, becoming an attraction for new vessel to land their catch in Kutaraja International Fishing Port, which initially only vessel 10-50 GT to $>100 \mathrm{GT}$, meaning that with the increase in infrastructure there is also an increase in activity. However, there is an increasing in infrastructure, the capacity of the new wharf of Kutaraja fishing port has not been able to compensate for the changes in activity that occur, especially if there arevessels with a size of $\geq 100$ GT that land the catch, where the vessel has a different vessel height size far from a medium vessel $20-50$ GT so that vessels with large and medium sizes cannot queue in the same server.According to [5],vessels will queue in the same server if the size of the vessel on the server tends to be the same. In addition to the different vessel sizes, the $100 \mathrm{GT}$ also has much more cargo than smaller vessel, so it takes longer in unloading [5] [6] [7]. Thus, in the initial observation there were many incidentsof vessel coming out of the queue because the queue was long enough that the commodity carried by the fish would rot and there was a lot of disposal of catches in the location. Based on this fact, anappropriate calculation is needed so that port service and performance can run optimally. Thus, the analysis of the queue of fishing vessels that unload catches at Kutaraja International Fishing Port needs to be done in an effort to improve service and port performance. The study aims to determine: the model of the queue of fishing vessels that land catches at Kutaraja International Fishing Port; the utility level of the system or the utilization rate of catch loading and unloading service facilities; and the waiting time of vessel in the queue at Kutaraja International Fishing Port.

\section{$2 \quad$ Methods}

\footnotetext{
* Corresponding author: muhammad@unsyiah.ac.id
} 


\subsection{Location and time}

Research in the field was conducted in March-May 2016, but the discussion was renewed through the study until 2021. Research location at Kutaraja Ocean Fishery Port, Banda Aceh, Aceh Province. Details of the research location can be seen through Figure 1.

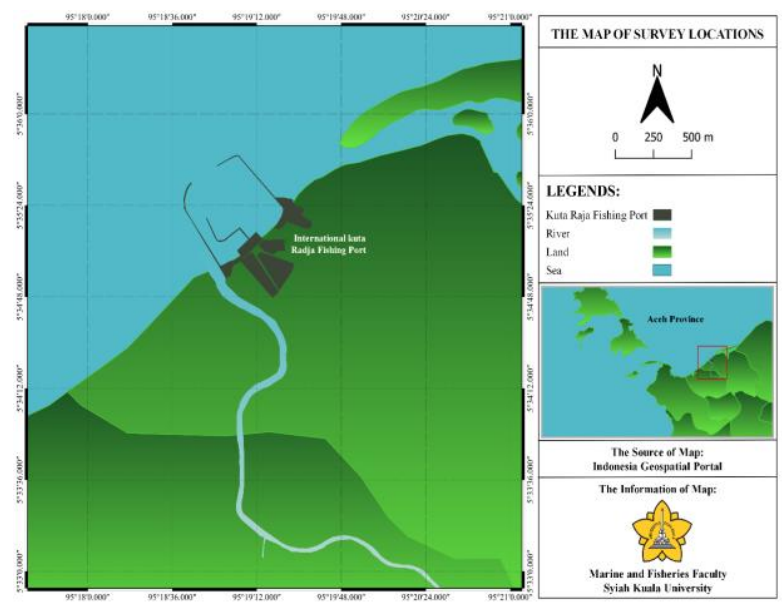

Fig. 1. Map of survey location.

\subsection{Data Collection}

The research method used is the observation method. Observation methods are methods used to obtain information in real terms by utilizing the five senses. The steps taken to obtain the data are as follows: primary data collection in the form of number of vessel arrivals, vessel arrival time, time of service of vessel union time [8]. Data collection is carried out during the port rush hour period that are in the morning on 06.00 am till afternoon on $04.00 \mathrm{pm}$, while secondary data in the form of data on the size of facilities and activities of Kutaraja International Fishing Port.

\subsection{Data Analysis}

To get the appropriate model, it must be done the selection of model functions that are in accordance with the circumstances in the field.Here are the steps used to determine the right model, namely grouping data based on arrival and service rates [9], looking for frequencies, finding raw deviations, testing data distributions, establishing parameters of the selected distribution. To establish the queue model, then there are several notations used, one of the notations used is kendall notation with the [10] following format:

\subsubsection{Queue Models Identifications in Kutaraja International Fishing Port}

Identification of the vessel queue model was analyzed using the Kendall DG model. The notation system is as follows:

$(\mathrm{a} / \mathrm{b} / \mathrm{c}):(\mathrm{d} / \mathrm{e} / \mathrm{f})$
Where:a is the distribution of arrivals, $b$ is the distribution of service time, $\mathrm{c}$ is the number of service facilities, $d$ is the discipline of queue, e is the maximum number of customers in the system, and $f$ is the population size of the customer

Standard notation that replaces $a$ and $b$ is: $M$ is the distribution of arrivals and the rate of service following the distribution of poisson, $D$ is service time, $G$ is distribution of public service time, GI is distribution of arrivals

Notation that replaces e and $\mathrm{f}$ is: $\mathrm{I}$ is The maximum number of customers (Infinite), $\mathrm{F}$ is The maximum number of customers (finite). The discipline used is First Come First Service (FCFS)

\subsubsection{Vessel arrival data distribution testing}

Distribution of vessel arrival data can be analyzed using kolmogorov smirnov with is hypothesis.

H0: arrival rate of poisson-distributed vessel

H1: the arrival rate of the vessel is not distributed poisson

Taraf significant $\alpha 0.05$

Statistical test $\mathrm{D}=|\operatorname{SoupS}(\mathrm{x})-\mathrm{F} 0(\mathrm{x})|$

where: $\mathrm{S}(\mathrm{x})$ is Cumulative distribution of vessel arrival data, F0(x)is Cumulative distribution of hypothesized distributions

Test criteria

H0is accepted at a significant level $\alpha 0.05$, if the D value $>$ thevalue of $D^{*}(a / 2)$

where: $D^{*}(\mathrm{a} / 2)=$ Is the critical value obtained from The Kolmogorov Smirnov table.

\subsubsection{Service-level distribution testing}

Distribution of vessel arrival data can be analyzed using kolmogorov smirnov with the hypothesis:

H0: service level of poisson-distributed vessel

H1: service level of vessel not distributed poisson

Taraf significant $\alpha 0.05$

Statistical test

$\mathrm{D}=\operatorname{Sup}|\mathrm{S}(\mathrm{x})-\mathrm{F} 0(\mathrm{x})|$

where: $\mathrm{S}(\mathrm{x})$ is cummulative distribution from vessel servive data, $\mathrm{F} 0(\mathrm{x})$ is cummulative distribution from distributuion that hipothesized.

Test criteria

H0is accepted at a significant level $\alpha 0.05$, if the D value $>$ thevalue of $D^{*}(a / 2)$

Information:

$\mathrm{D} *(\mathrm{a} / 2)$

Where: D Is the critical value obtained from the table Kolmogorov Smirnov. 


\subsubsection{Queue standard formula calculation}

In solving the queue problem, then previously there are assumptions that must be met. There are the following assumptions [11]:

Tabel 1. Type of assumption.

\begin{tabular}{|c|c|}
\hline No & Type of Assumption \\
\hline 1 & $\begin{array}{c}\text { Arrival distribution must be distributed } \\
\text { poisson }\end{array}$ \\
\hline 2 & Service distribution mut be exponential \\
\hline 3 & Queue dicipline follows FCFS \\
\hline 4 & The number of consumers is unlimited \\
\hline 5 & Service level $>$ arrival rate \\
\hline
\end{tabular}

With the fulfillment of assumptions, the queue problem can be solved by the following equations:

$p=\frac{\lambda}{\mu}$

$P o=\frac{1}{N} \sum_{N=0}^{c-1} \quad \frac{\left(\frac{\lambda}{\mu}\right)}{N i}+\frac{\left(\frac{\lambda}{\mu}\right)}{c !\left(1 \frac{\lambda}{c \mu}\right)}$

$L q=\frac{\left(\frac{\lambda}{\mu}\right)^{c} \lambda \mu}{(c-1) !(c \mu-\lambda)^{2}} P o$

$L s=L q+\frac{\lambda}{\mu}$

$W q=\frac{L q}{\lambda}$

$W s=W q+\frac{1}{\mu}$

Where: $\lambda$ is number of arrivals of union vessel of time. $\mu$ is number of vessel served by union time, $Q$ is system utility factor, Po is chance of 0 vessel in the system (no customers), Lq is average number of vessel in the queue, $\mathrm{Wq}$ is the average wait time for vessel in the queue, Ws is Average wait time for vessel in the system, and $\mathrm{C}$ is number of facilities in service.

\section{$3 \quad$ Result and discussion}

\subsection{General conditions of Kutaraja International Fishing Port}

Kutaraja International Fishing Port is equipped with various facilities to support fisheries business activities [12]. Such facilities include the main and supporting facilities of the three facilities, which play the most role in maintaining the safety of the vessel docked and ensuring the activity of the vessel at the time of entry to the port is the main facility [13]. According to [14],one of the main facilities that play the most role in maintaining the smooth operation of the vessel at the time of dismantling the catch is the wharf [15]. The wharf at Kutaraja International Fishing Ports is known to be divided into 4 pias. that each pias has a different size. Pias II is the Wharf that most often used to unload catches because of its location right in front of the fish auctions building. The size of this wharf is $100 \mathrm{~m} \times 4 \mathrm{~m}$ with an open type.

During fishing seasons such as March-April, activity at Kutaraja International Fishing Port is more dense than usual, this tends to cause queues. The queues that occur can be seen with the vessel that are layered. Because the dominant activity is carried out on the pier pias II. In pias II, there are vessel of various sizes that land catches, this causes uneven vessel queues on each server, especially if there are vessel with a size of $\geq 100$ GT that land, then the queue on the servers of other vessel smaller to be longer than 4 layers to 8 layers. This happens because large and small vessel cannot perform service on the same server due to the size gap of the vessel. In addition, large vessel also have a fairly long unloading time, this is due to the working hours of unloading Kutaraja International Fishing Port which is only 8 hours / day so that not all the contents of large vessel can be dismantled in a day. As a result, vessel that are too long in the queue can suffer losses caused by fish that decline in quality.

\subsection{Identify Queue Models at Kutaraja International Fishing Port}

The queue model on Kutaraja International Fishing Port follows the pattern of double lane queues. Idelanya Kutaraja International Fishing Port has 4 service servers for loading and unloading activities (Figure 3). The discipline applied is FCFS (First come first service) or called the first come first served [16]. At pias II, the dock, the server can be 4 if the vessel that landed is a medium-size vessel $\geq 50$ GT, but if a large vessel lands, then the available for medium-sized vessel is only 2-3 servers, this results in increased queues.

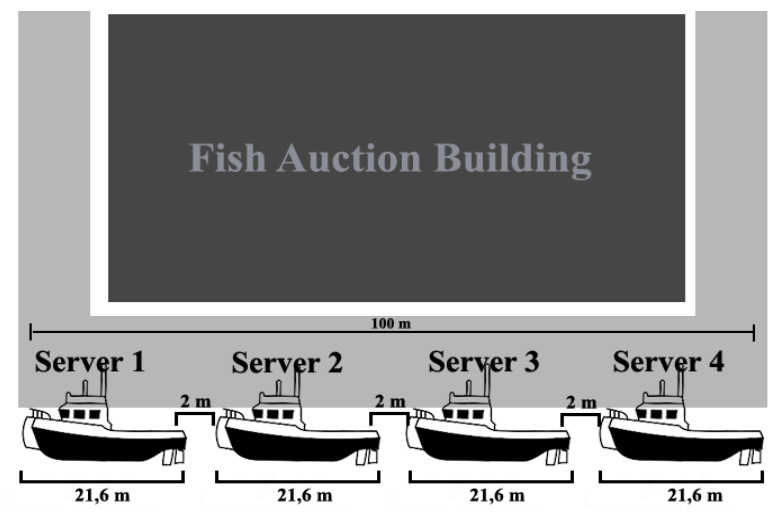

Fig. 2. Simulation Of Fishing Vessel Queue In Kutaraja International Fishing Port

Vessels visiting Kutaraja International Fishing Port generally do various activities, such as uncovering catches. The demolition of the catch was carried out at pias II pier. Based on the pictures, vessel visits in March-April tend to fluctuate. 
Arrival rate of fishing vessel in Kutaraja International Fishing Port

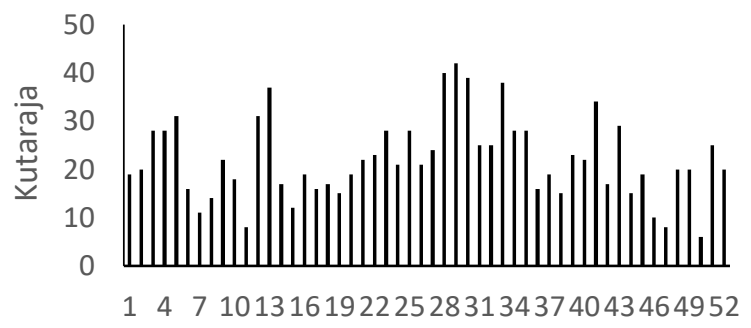

day

Fig. 3. Arrival rate of foshing vesssel in Kutaraja International Fishing Port

\subsection{Queue System Utility Calculation at Kutaraja International Fishing Port}

Seen in tabel 2, from the results of calculations, it is known that the arrival rate of fishing vessels is 22 vessel / day with an average service time of 16 vessels / day or 2 hours / vessel with 4 service servers. The results of the analysis showed that the arrival rate was much higher than the rate of service, indicating that there was a problem in the queue. This can be seen from the queuing intensity value that indicates the value of $\geq 1$. The intensity value will be declared stable if it is worth 0 .

Table 2. the result of utillity system queue

\begin{tabular}{|c|c|}
\hline Queue model variables & Result \\
\hline $\begin{array}{c}\text { the average arrival rate into } \\
\text { the system }(\lambda)\end{array}$ & 22 units/day \\
\hline M service level & 16 Units/day \\
\hline The number of servers (s) & 4 units \\
\hline Queue intensity $\rho$ & 1,37 \\
\hline $\begin{array}{c}\text { Chances are there are no } \\
\text { Vessel in the queue } \rho \text { o }\end{array}$ & 0,08 \\
\hline $\begin{array}{c}\text { Average number of Vessel in } \\
\text { Lq queue }\end{array}$ & 1,42 units \\
\hline $\begin{array}{c}\text { Average number of Vessel in } \\
\text { the Ls system }\end{array}$ & 0,96 hours \\
\hline $\begin{array}{c}\text { Average time of vessel in } \\
\text { Wq queue }\end{array}$ & 3,84 hours \\
\hline $\begin{array}{c}\text { Average time of Vessel in } \\
\text { the Ws system }\end{array}$ & \\
\hline
\end{tabular}

The chance of no vessel in the system at Kutaraja International Fishing Port is 0,08. The average number of vessel queuing in the system is 0,05 vessel. Thus the vessel that come to Kutaraja International Fishing Port occur aof 0,96 hours or almost 1 hour. The average number of vessel in the system is 1,42 units with an average waiting time of 3,84 hours. The number of vessel in the system must be greater than the number of vessel in the queue because the number of vessel in the system is the number of vessel in the queue plus the vessel servedi. In addition, the average amount of time in the system should also be greater than the average time of queue [17].

Based on the description above, it can be concluded that what causes high queues is the entry of large vessel. As for the efforts that can be made to accelerate the demolition of fish in Kutaraja International Fishing Port, among others, with the addition of aids such as cranes so as to maximize the working time of fish demolition on high capacity vessels [18].

\section{Conclusion}

The queue model at Kutaraja International Fishing Port is $(\mathrm{M} / \mathrm{M} / 4):(\mathrm{FCFS} / \mathrm{I} / \mathrm{I})$ with a dual-lane queue system and one stage of service (MultiChannel SinglePhase). The characteristics of queues at Kutaraja International Fishing Port are unlimited population (infinite), queue length is also unlimited (infinite), the pattern of arrival of poisson-distributed vessel, exponential distribution vessel service and queue discipline is First Come First Served (FCFS). The average waiting act of a vessel in a queue $(\mathrm{Wq})$ is 0 hours (no one is in line), while the average waiting time of the vessel in the system (Ws) is 3 , 4hours.

\section{Refferences}

1. T. Rizwan, Z Jalil, A Akhyar, H Husaini. Oceanographic Factors As The Indicators for Shipyard Industry Development in Kutaraja Fishing Port: Preliminary Study. J. ecol. Eng, vol. 9, no. 22, pp. 237-245 (2021).

2. T. Rizwan, O. Kandi, Z. Jalil, I. Setiawan, R. Maulana, D. M. Ranti, I. Zulfahmi, Y. Muchlis, The Analysis of Clean Water Need For Fishing Activities in Kutaraja Fishing Port, Aceh Indonesia. Australian Journal of Maritime \& Ocean Affairs., pp. 1-12 (2020).

3. P. E. Alayya, H. Boesono, D. Wijayanto. The strategies of Pekalongan fishing port development. IOP Conf. Series: Earth and Environmental Science, vol. 530, pp. 1-10 (2020).

4. R. A. Najah, E. Lubis, R. Muninggar. Existence of Facilities by Activities at Lampulo Beach Fishing Port, Banda Aceh. Marine Fisheries. vol. 3, no. 1, pp. 55-70 (2012).

5. D. Zhang, M. Sikveland, O. Hermansen, Fishing fleet capacity and profitability. Marine policy, vol. 88, pp. 116-121 (2018).

6. S. Hisamune, N. Kimura, K. Amagai, "Ergonomic Evaluationina in a Case Study on The Behaviour of Purse Seine Fishing Vessel workers. Fisheries Enginering. vol. 42, 1, 9-17 (2005). 
7. R. Rahayu. The Utillization of Lampulo Fishing Port Main Facilities (Universitas Syiah Kuala, Aceh, 2016).

8. M. Rahardjo, The Methods of Data Collection of Qualitative Research (Malang: UIN Malang, 2011).

9. S. Syarif, N. Alimina, A. Mustafa, "The Models of Queue of Kendari International Fishing Port," Jurnal Manajemen Sumber Daya Perairan, vol. 4, no. 1, 231-242 (2019).

10. K. a. V. Vladimir. Mathematical Methods in Queuing Theory (Moscow: Kluwer Academic, 1994).

11. B. Murdiyanto. Fishing Port (IPB Bogor, 2004).

12. A. Rahmah, M. Rizayani, C.Chaliluddin. The influence of the service quality of the International Lampulo Fishing Port on the smooth operation of fishing operations. Depik, vol. 7, no. 1 (2018).

13. E. Lubis and Pujiono. The Needs for Main Facilities and Availability of the Capture Fisheries. JIPK, vol. 12, no. 2, pp. 224-235, (2020).

14. E. Lubis and N. Mardiana. Role of Fish Landing Place (PPI) Facilities on Fish Landing. JTPK, vol. 2, no. 1, pp. 1-10 (2011).

15. M. Wang, W Chen, A Epherimdes. Real-Time Reconstruction of a Counting Process Through First-Come-First-Serve Queue Systems. IEEE Explore, vol. 66, no. 7, pp. 4547 - 4562, (2020).

16. R. Khabibah, H. T. Sutanto, Y. P. Astuti. Queue System of Vessel Unloading Services at The Diamond Terminal, Tanjung Perak Port Surabaya. J. Ilmiah Matematika, vol. 2, no. 2, (2013).

17. A. A. Rahayu, Sugito, Sudarno. Model Analysis of Time Inter-Arrival and Service Time at The Cash Payment Section in Installation Installation Dr Kariadi Hospital, Semarang .Statistics Nasional Proceeding, pp. 249-261, (2013).

18. Johansen, N. S., Vänninen, I., Pinto, D. M., Nissinen, A. I., \& Shipp, L, "In the light of new greenhouse technologies: 2. Direct effects of artificial lighting on arthropods and integrated pest management in greenhouse crops. Annals of Applied Biology, Vols. 159(1), 1-27., (2011). 